\title{
CONCOMITANT MULTIPOTENT AND UNIPOTENT DENTAL PULP PROGENITORS AND THEIR RESPECTIVE CONTRIBUTION TO MINERALISED TISSUE FORMATION
}

\author{
S. Lacerda-Pinheiro ${ }^{1,2, \#, ~ S . ~ D i m i t r o v a-N a k o v ~}{ }^{1, \#}$, Y. Harichane $^{1}$, M. Souyri ${ }^{3}$, L. Petit-Cocault ${ }^{3}$, L. Legrès ${ }^{4}$, \\ A. Marchadier ${ }^{1,5}$, A. Baudry ${ }^{1}$, S. Ribes ${ }^{2}$, M. Goldberg ${ }^{1}$, O. Kellermann ${ }^{1}$ and A. Poliard ${ }^{1,2, *}$ \\ ${ }^{1}$ INSERM UMR-S 747, Université Paris Descartes, Sorbonne Paris Cité, Paris, France \\ ${ }^{2}$ Laboratoire de Biothérapie de l'Organe Dentaire, EA2496, Faculté de Chirurgie Dentaire, Université Paris Descartes, Sorbonne \\ Paris Cité, Montrouge, France \\ ${ }^{3}$ CNRS, UMR 7622, Université Pierre et Marie Curie Paris, France \\ ${ }^{4}$ Inserm UMR S728, Université Paris-Diderot, Institut Universitaire d'Hématologie, Hôpital Saint-Louis, Paris, France \\ ${ }^{5}$ Useful Progress, 23, rue d'Anjou, Paris, France \\ \# both authors contributed equally to this work
}

\begin{abstract}
Upon in vitro induction or in vivo implantation, the stem cells of the dental pulp display hallmarks of odontoblastic, osteogenic, adipogenic or neuronal cells. However, whether these phenotypes result from genuine multipotent cells or from coexistence of distinct progenitors is still an open question. Furthermore, determining whether a single cell-derived progenitor is capable of undergoing a differentiation cascade leading to tissue repair in situ is important for the development of cell therapy strategies. Three clonal pulp precursor cell lines (A4, C5, H8), established from embryonic ED18 first molars of mouse transgenic for a recombinant plasmid adeno-SV40, were induced to differentiate towards the odonto/osteogenic, chondrogenic or adipogenic programme. Expression of phenotypic markers of each lineage was evaluated by RTPCR, histochemistry or immunocytochemistry. The clones were implanted into mandibular incisors or calvaria of adult mice. The A4 clone was capable of being recruited towards at least 3 mesodermal lineages in vitro and of contributing to dentin-like or bone formation, in vivo, thus behaving as a multipotent cell. In contrast, the $\mathrm{C} 5$ and $\mathrm{H} 8$ clones displayed a more restricted potential. Flow cytometric analysis revealed that isolated monopotent and multipotent clones could be distinguished by a differential expression of CD90. Altogether, isolation of these clonal lines allowed demonstrating the coexistence of multipotential and restricted-lineage progenitors in the mouse pulp. These cells may further permit unravelling specificities of the different types of pulp progenitors, hence facilitating the development of cell-based therapies of the dental pulp or other cranio-facial tissues.
\end{abstract}

Keywords: Dental pulp progenitor cells; differentiation; implantation; dentin regeneration; mouse incisor; mouse calvarium.

*Address for correspondence:

Anne Poliard,

Laboratoire de Biothérapie de l'Organe Dentaire,

EA2496, UFR d'Odontologie, Université Paris-Descartes, Sorbonne Paris Cité, 1 rue Maurice Arnoux,

F-92120 Montrouge, France

Telephone Number: +33158076784

FAX Number +33158076728

E-mail: anne.poliard@parisdescartes.fr $\beta G P$ : beta-glycerophosphate

AA: ascorbic acid

BSP: Bone sialoprotein

Col I and II: Collagen type I and II

DEX: dexamethasone

DMEM: Dulbecco's Modified Eagle Medium

DMP1: Dentin matrix protein 1

DSP: Dentin sialoprotein

ECM: extracellular matrix

ES: embryonic stem cells

FCS: foetal calf serum

GAPDH: Glyceraldehyde-3-phosphate dehydrogenase

HA/TCP: Hydroxyapatite/tri-calcium phosphate

HE: Haematoxylin and eosin

IBMX: 3-isobutyl-1-methylxanthine

LPL: Lipoprotein lipase

MSC: Mesenchymal stromal/stem cells

PBS: phosphate buffered saline

PFA: paraformaldehyde

PPAR $\gamma 2$ : Proliferator-activated receptor gamma 2

TGFß1: Transforming growth factor beta 1

\section{Introduction}

During early stages of odontogenesis, interactions between epithelial and mesenchymal cells lead to differentiation of an ectomesenchymal cell population into post-mitotic odontoblasts that are responsible for the secretion of primary dentin. In adult functional teeth, odontoblasts secrete secondary dentin. In contrast to bone, which has the capacity to repair and remodel, odontoblasts and pulp cells display only limited reparative properties (Murray et al., 2002). In wounded adult teeth, odontoblasts retain the ability to respond to mild environmental stimuli and to focally up-regulate their secretory activity, leading to reactionary dentin formation (Smith et al., 1995). More intensive stimuli like carious decay, free monomer released from dental biomaterials or dental trauma can lead to the death of the existing odontoblast population. In such cases, a reparative dentin formation requires the differentiation of a new generation of odontoblast-like cells, presumably arising from a precursor population recruited within the pulpal tissue. Adult dormant dental pulp cells can be stimulated to produce reparative dentin 
by implantation of various biomolecules (Goldberg and Smith, 2004). In response to these agents, the pulp implements a reaction that successively involves (1) commitment (2) proliferation (3) differentiation of a subpopulation of cells displaying osteoblast-like properties (Nakashima et al., 2004; Ruch, 1998; Six et al., 2002; Tziafas et al., 1998). Still, the cellular and molecular events underlying the regenerative capacity of dental pulp cells remain largely unknown. In particular, the origin and precise identity of the progenitors have remained elusive. Cells from the subodontoblastic layer of Hoehl (Sloan and Smith, 2007), the Rouget's pericytes (perivascular cells), undifferentiated mesenchymal cells or fibroblasts (Fitzgerald et al., 1990) have all been proposed as potential progenitors mediating pulp repair. More recently, the presence of distinct cell populations displaying stem cell properties has been established in the post-natal human dental pulp (Gronthos et al., 2000; Miura et al., 2003; Laino et al., 2005; Pierdomenico et al., 2005; Iohara et al., 2006; Kerkis et al., 2006). In response to stimulation, some cells residing in the adult pulp can be recruited to display features of the osteoblastic, adipogenic, chondrogenic or neuronal lineages in vitro and/or in vivo (for review, see Huang et al., 2009). They thus present similarities with mesenchymal stem cells (MSCs) of the bone marrow (Shi et al., 2001) with the great advantage of being accessible through a less traumatic process. Moreover, due to their neural crest developmental origin, they might be more adapted in repairing neuronal or cranio-facial lesions.

However, all available data has been obtained on uncloned cell populations. Therefore, it is not yet clear whether multipotent/pluripotent progenitors really exist within the pulp, as demonstrated in the bone marrow, and/ or whether the different phenotypes result from the coexistence of distinct types of more restricted progenitors (Muraglia et al., 2000). Another crucial question is whether clonal pulpal progenitors can efficiently contribute in vivo to the repair of dental or other tissues. Indeed, since a tissue is constituted of heterogeneous cell populations, an apparent identical phenotype may in fact include a series of cells at different degrees of maturity. As a consequence, some progenitor cells might be more efficient than others in performing tissue repair and their specific "fishing out" might considerably improve the prospect of the therapeutic processes. These points constitute important issues for cell-based regenerative therapies.

Using mice transgenic for a recombinant adenoSV40 plasmid, we have established clonal cell lines from dental pulp cultures of embryonic day 18 (ED18) molar by limiting dilution (Priam et al., 2005). These cell lines maintain a stable and undifferentiated phenotype under long-term standard culture conditions. Three independent clones, (C5), (H8) and (A4) have been shown to display precursor properties and to be able to engage in the odontoblastic program in response to amelogenin small molecular weight spliced isoforms (Lacerda-Pinheiro et al., 2006).

In the present report, we show that two pulpal clones, $\mathrm{C} 5$ and $\mathrm{H} 8$, behave as monopotent progenitors in vitro, able to promote osteodentin formation in vivo when implanted in the mouse incisor. The third clone, A4, displays the properties of a multipotent progenitor. Altogether, these results provide strong evidence that, in the mouse dental pulp, multipotent mesenchymal progenitors co-exist with more restricted precursors.

\section{Materials and Methods}

\section{Cell culture and differentiation}

50 clonal cell lines have been derived from first molar tooth germs of E18 mouse embryos transgenic for a recombinant plasmid adeno-SV40 (Priam et al., 2005). Among these clones, the cell lines A4, C5 and H8 (previously referred as respectively Top3, Top1 and Top2 in (Priam et al., 2005)) as well as the A11, G10 and G7 cell lines obtained in parallel were cultured as described (Priam et al., 2005). A stromal progenitor cell line, MOpK4, was derived from the bone marrow of an adult $\mathrm{pK} 4$ transgenic mouse (Laoide et al., 1996), according to (Pereira et al., 1998), and cultured as the pulpal cell lines. R1 mouse embryonic stem cells (ES) were cultured as in (Robertson, 1987). To induce the odontogenic program, pulpal cells were grown to confluence and switched to $1 \%$ FCS supplemented Dulbecco's Modified Essential Medium (DMEM) containing $\beta$-glycerophosphate $(\beta \mathrm{GP})(5 \mathrm{mM})$, ascorbic acid (AA) $(50 \mathrm{mg} / \mathrm{mL})$ and dexamethasone (DEX) $\left(10^{-7}\right.$ $\mathrm{M})$. For osteogenic and chondrogenic differentiation, cells were seeded on untreated plastic Petri dish $\left(10^{6}\right.$ cells $\left./ \mathrm{mL}\right)$ in DMEM supplemented with $10 \%$ foetal calf serum (FCS). In these conditions cells cannot readily attach and spread on the plastic. Instead they form 3-dimensional (3D) aggregates (Poliard et al., 1999). After 10 days, the aggregates were switched to the differentiation medium. Chondrogenic differentiation was performed in serum-free medium containing $1 \mathrm{mM}$ pyruvate and $1 \mathrm{mM}$ cysteine and initiated by addition of $10 \mathrm{ng} / \mathrm{mL}$ TGFß1 (Chemicon, Temecula, CA, USA), $10^{-7} \mathrm{M}$ DEX, $50 \mu \mathrm{g} / \mathrm{mL}$ AA and 10 $\mu \mathrm{g} / \mathrm{mL}$ insulin transferrin selenium (Invitrogen, Carlsbad, CA, USA). Osteogenic differentiation was performed in DMEM supplemented with $1 \%$ FCS and induced by addition of $5 \mathrm{mM}$ BGP and $50 \mu \mathrm{g} / \mathrm{mL}$ AA. Adipogenic differentiation was induced in confluent cell cultures as in (Zuk et al., 2002). Control cultures (monolayers and aggregates) were maintained in medium without inducers. All cultures were renewed every 3-4 days. The chemicals were from Sigma (Sigma-Aldrich, St Louis, MO, USA) unless otherwise specified.

\section{Cell preparation for implantation}

The pulpal or ES cells were implanted in the incisor as a micromass (Ballock and Reddi, 1994). To this end, 2.5 x $10^{5}$ cells were inoculated in an Eppendorf tube, briefly centrifuged at $1,000 \mathrm{rpm}$ and the resulting pellet let incubated overnight at $37{ }^{\circ} \mathrm{C}$ to form the micromass. For transplantation in the calvaria, $5 \times 10^{6}$ pulpal or MOpK4 cells were suspended in $1 \mathrm{~mL}$ DMEM containing 40 mg of hydroxyapatite/tri-calcium phosphate (HA/TCP) (Atlantik ${ }^{\circledR}$ Medical Biomat, Vaux en Velin, France) and incubated for $90 \mathrm{~min}$ at $37^{\circ} \mathrm{C}$ as described (Mankani et al., 2006). 
Table 1. Primers used in RT-PCR analyses.

\begin{tabular}{|c|c|c|}
\hline Gene & 5 ' DNA sequence 3 ' & Product Size (bp) \\
\hline PPAR $\gamma 2$ & $\begin{array}{l}\text { sense:5'-CCATAGTGGAAGCCTGATGC-3' } \\
\text { antisense:5'-TGGGTGAAACTCTGGGAGAT-3' }\end{array}$ & 346 \\
\hline LPL & $\begin{array}{l}\text { sense:5'-GTGTTGCTTGCCATTCTC-3', } \\
\text { antisense:5'-TCTCCTGATGACGCTGAT-3' }\end{array}$ & 479 \\
\hline Sox9 & $\begin{array}{l}\text { sense: 5'-CTGAACGAGAGCGAGAAGAG-3' } \\
\text { antisense:5'-GGACCCTGAGATTGCCC-3' }\end{array}$ & 266 \\
\hline Col II & $\begin{array}{l}\text { sense : 5'-CGCTGGTGCTGCTGAC-3' } \\
\text { antisense: 5'-CCTTTCTGCCCCTTTGG-3' }\end{array}$ & $\begin{array}{l}A=300 \\
B=100\end{array}$ \\
\hline Aggrecan & $\begin{array}{l}\text { sense: 5'-CCGTCAGATACCCCATTG-3' } \\
\text { antisense: 5'- CAGCCAGCATAGCACTTG-3' }\end{array}$ & 280 \\
\hline GAPDH & $\begin{array}{l}\text { sense:5'-TGAAGGTCGGTGTGAACGGATTTGGC-3' } \\
\text { antisense:5'-CATGTAGGCCATGAGGTCCACCAC-3' }\end{array}$ & 982 \\
\hline
\end{tabular}

\section{Flow cytometric analysis}

Standard flow cytometry techniques were used to determine the cell surface epitope profile of the pulpal clones. Briefly, cells were incubated for $15 \mathrm{~min}$ at $4{ }^{\circ} \mathrm{C}$ with saturating concentration of antibodies to the following mouse epitopes: Sca-1, CD90-Thy-1, 3G5-MAP1b, CD146 and CD24 (Abcam, Cambridge, UK), CD31-PE, c-kit, CD29 and CD105 (BD Pharmingen, San Diego, CA, USA), CD34 (BioLegend, San Diego, CA, USA), CD44 and CD45 (Fitzgerald Industries International, Concord, MA, USA). Cells were washed in PBS and incubated with secondary antibodies coupled either to Phyco-erythrine (PE) (Beckman Coulter, Fullerton, CA, USA) or to Alexafluor 488 (Molecular probes, Eugene, Or, USA). Cell suspensions were then analysed on a flow cytometer (FACSCalibur, Becton Dickinson, San Jose, CA, USA) using the Cell Quest Software. Negative controls were $\operatorname{IgG}(\mathrm{H}+\mathrm{L})-\mathrm{PE}$ and $\operatorname{IgG}(\mathrm{H}+\mathrm{L})$ Alexafluor 488. Statistical analysis was performed using the Mann-Whitney test.

\section{RNA isolation RT-PCR analyses}

Total RNA was isolated by affinity chromatography using RNeasy ${ }^{\circledR}$ Midi kit (Qiagen, Hilden, Germany). The first-strand cDNA synthesis was performed with oligo dTprimers (Invitrogen). Semi quantitative PCR amplification was carried out according to the manufacturer's instructions using mouse-specific primers (see Table 1 for sequence, temperature and size of amplicons). Glyceraldehyde3-phosphate dehydrogenase (GAPDH) was used as an internal control. Quantitative real time PCR was performed at $60{ }^{\circ} \mathrm{C}$ using ABsolute SYBR Green Rox Mix, (Thermo Scientific), according to the supplier's direction. The relative expression of DSPP, DMP1 and TATA binding box protein (TBP) transcripts was calculated and compared with the expression in the D0 control. The primers were as follows, TBP: forward: 5'-caaacccagaattgttctcett-3' and reverse: 5'-atgtggtcttcctgaatccct-3', DMP1: forward: 5' -tgaagagaggacgggtgatt-3' and reverse: 5'-cggtctgtactggcetctgt-3' and the DSPP primers were obtained from Qiagen.

\section{Immunocytochemical and histochemical studies}

Aggregates induced towards chondrogenic differentiation were fixed in PBS containing $4 \%$ paraformaldehyde (PFA) and embedded in $4 \%$ low melting agarose before inclusion in Paraplast Plus (Kendall, Mansfield, MA, USA). Immunocytochemistry was performed on $7 \mu \mathrm{m}$ sections as previously described (Locker et al., 2004). The antibodies used were: a mouse monoclonal anti-type II collagen (Col II) (Neomarkers Inc., Fremont, CA, USA) and a rabbit polyclonal anti-Sox9 (Abcam). Cartilage proteoglycan matrix was stained with Alcian blue at $\mathrm{pH} 1$ or with Safranin O.

Aggregates induced towards osteogenic differentiation were fixed in PFA $4 \%$, dehydrated in acetone and embedded in methyl methacrylate (Merck, Darmstadt, Germany), as described (Adam et al., 2000) and treated as in (Rammelt et al., 2007) before immunohistochemical analysis which was performed on $4 \mu \mathrm{m}$ aggregate sections using rabbit polyclonal anti-dentin sialoprotein (DSP), anti-bone sialoprotein (BSP), (Dr Larry Fisher, NIH, Bethesda USA), and anti-type I collagen (Col I) (Chemicon, Temecula, CA, USA). Matrix mineralisation was evaluated by both Alizarin red and Von Kossa staining. For adipogenic differentiation, the presence of fat droplets was evaluated by Oil red $\mathrm{O}$ staining.

In vivo transplantation procedure, microscanner and immunohistochemical analyses

All animal procedures were performed under an institutionally approved protocol for use of animals in research. Ten-week-old mice C57Bl-6 male (25 g) (Charles Rivers, l'Arbresle, France) ( $n=6$ for each group) were anaesthetised by intraperitoneal administration of ketamine (100 mg/kg of body weight)/xylazine $(10 \mathrm{mg} / \mathrm{kg}$ of body weight). Cell implantations in the incisor were performed as described (Lacerda-Pinheiro et al., 2008).

An incision of $1 \mathrm{~cm}$ long was first made through the skin to access the subjacent muscle layer, along a theoretical line joining the auditory meatus and the lip commissure. The masseter muscle was incised along its longitudinal 
axis. The periosteum was scraped with a curette and the bone surface exposed between the posterior angle of mandible and the molars block, approximately $1 \mathrm{~mm}$ above the mandibular basal border. The point where the outer oblique line crosses the apical loop of incisor was selected as the site for pulp exposure. The hole through bone and tooth was formed using a low speed dental drill with a round tungsten-carbide burr (size 6 - DentisplyMaillefer, Ballaigues, Switzerland).

Control animals (Sham group) were treated identically but without cell implantation.

For calvaria implantations ( $n=3)$, a $5 \mathrm{~mm}$ full-thickness cranial defect (critical size defect) was prepared with a trephine (Euroteknika SA, Sallanches, France) attached to an electric motorised handpiece. The defects were filled with HA/TCP alone (controls) or HA/TCP associated with cells.

Animals received $1 \mathrm{mg} / \mathrm{kg}$ meloxican (Metacam, Boehringer Ingelheim, Reims, France) as analgesic immediately after surgery and were euthanised postoperatively by cervical dislocation 10 days or 3 months after implantation in the incisor or calvaria, respectively.

Mandibles were subjected to micro-scanner analyses with a 1072 Skyscan ${ }^{\circledR}$ micro-CT (Skyscan $\AA$, Kontich, Belgium) as described in (Lacerda-Pinheiro et al., 2008). For immunohistochemical analyses, mandibles and calvaria were fixed in PFA $4 \%$ at $4{ }^{\circ} \mathrm{C}$ overnight, and demineralised for 2 months in buffered EDTA $4.13 \%$. Both tissues were dehydrated in graded ethanol and embedded in Paraplast Plus. $7 \mu \mathrm{m}$ thick sections were stained with Masson's trichome or haematoxylin-eosin (HE) and treated for immunohistochemistry as stated above.

\section{Laser microdissection and PCR analysis}

Laser microdissection was performed with a PALM Robot microbeam system (PALM Microlaser Technologies, Zeiss Micro-Imaging, Munich, Germany) coupled to an inverted Olympus IX-81 microscope. Microdissections were performed on $7 \mu \mathrm{m}$-thick paraffin-embedded incisor or calvaria sections spread on Membrane slides (PALM Microlaser Technologies, Bernried, Germany). After a brief deparaffinisation in toluene, areas of interest were ablated by UV laser and catapulted directly into the cap of a microfuge tube containing $20 \mu \mathrm{L}$ of the lysis buffer from the SmartDNAdem kit (Adamtech, Pessac, France). DNA extraction was made according to manufacturer's instructions. PCR analysis was performed (35 cycles at $58{ }^{\circ} \mathrm{C}$ ) to evaluate the presence of SV40 large $\mathrm{T}$ antigen using the following primers: sense 5'-TCTAACAAAAACTCACTGCGT-3' and antisense: 5'-AAAAGCGGGTTGATAGCCTAC-3'.

\section{Results}

\section{Dental pulp clones exhibit in vitro precursor properties with distinct differentiation potentials}

We have established clonal cell lines from the dental pulp of ED18 mice embryos transgenic for a recombinant plasmid adeno-SV40, which display properties of odontoblastlike progenitor cells (Priam et al., 2005). Three of these clones were selected on their pattern of odontoblastic marker expression and analysed to investigate whether they corresponded to precursor cells univocally committed to the odontoblastic lineage or whether they behaved as genuine mesenchymal stem cells able to engage in osteogenic, chondrogenic or adipogenic differentiation. As previously reported (Lacerda-Pinheiro et al., 2006), the 3 cell lines can be recruited towards the odontogenic program by treatment with small molecular weight amelogenins, as shown by an up-regulation of dentin sialoprotein (DSP) transcript expression. Thus, the 3 clones appear to possess an odontoblastic potential. Additional data indicated that they could correspond to precursors at different stages of commitment. Indeed, 15 days of monolayer culture in odonto/osteogenic medium (AA/ $\beta \mathrm{GP} / \mathrm{DEX})$, led the A4 cells to form numerous mineralised foci as inferred by Alizarin red and Von Kossa staining (Fig. 1A, a and $\mathrm{b}$, respectively). Mineralisation began to be visually detectable in the A4 cell culture as soon as day 5 and was accompanied by a strong stimulation in both the DMP1 and DSPP expression, as shown by qPCR (Fig. 2). In contrast, $\mathrm{C} 5$ and $\mathrm{H} 8$ cells did not exhibit any mineralisation (Von Kossa staining, Fig. 1A, c and d respectively), even after 30 days of induction in the same culture conditions and, accordingly DMP1 and DSPP expression was only weakly stimulated (Fig. 2). These observations indicate that the three independent cell lines may differ in their capacity to respond to recruiting agents to get engaged in an odonto/ osteogenic programme.

In vivo skeleton formation and bone repair depend critically on the condensation of mesodermal stem cells. Accordingly, induction of the osteogenic or chondrogenic differentiation was performed with the pulpal cells seeded in Petri dishes that have not been treated for tissue culture, to promote nodule formation rather than attachment to the plastic substrate (Locker et al., 2004). In such 3D conditions, $\mathrm{C} 5$ and $\mathrm{H} 8$ failed to establish efficient cell-cell contacts and rapidly lost viability. In contrast, the A4 cells had the intrinsic capacity to form 3D aggregates (Fig. 7C), as typical mesenchymal progenitors. After 10 days, as the cell nodules cease to increase in size, they were induced towards the osteogenic or chondrogenic program. Their potential for osteogenic differentiation was evaluated after 2 weeks of culture in osteogenic medium. Remarkably, mineralisation occurs in more than $90 \%$ of the aggregates as judged by Von Kossa staining of aggregate sections (Fig. 1Ba). Immunocytochemical analyses revealed the formation of a Col I extracellular matrix (ECM) (Fig. 1Bd) and the presence of BSP (Fig. 1Be), while DSP was totally undetectable (Fig. 1Bf). Col I matrix deposition and mineralisation were not observed in untreated control aggregates (Fig. 1Bc and b respectively).

After 10 days of culture in chondrogenic medium, histochemical and immunocytochemical analyses revealed that more than $90 \%$ of the A4 nodules presented chondrocyte-like cells embedded in an ECM enriched in glycosaminoglycans, as revealed by Alcian blue or safranin O staining (Fig. 1Cc and Fig. 7C, respectively). Furthermore, all the cells displayed a strong signal for Sox9 in their nuclei (Fig. 1Cd) and type II collagen in the extracellular space (Fig. 1Ce). Untreated A4 aggregates 

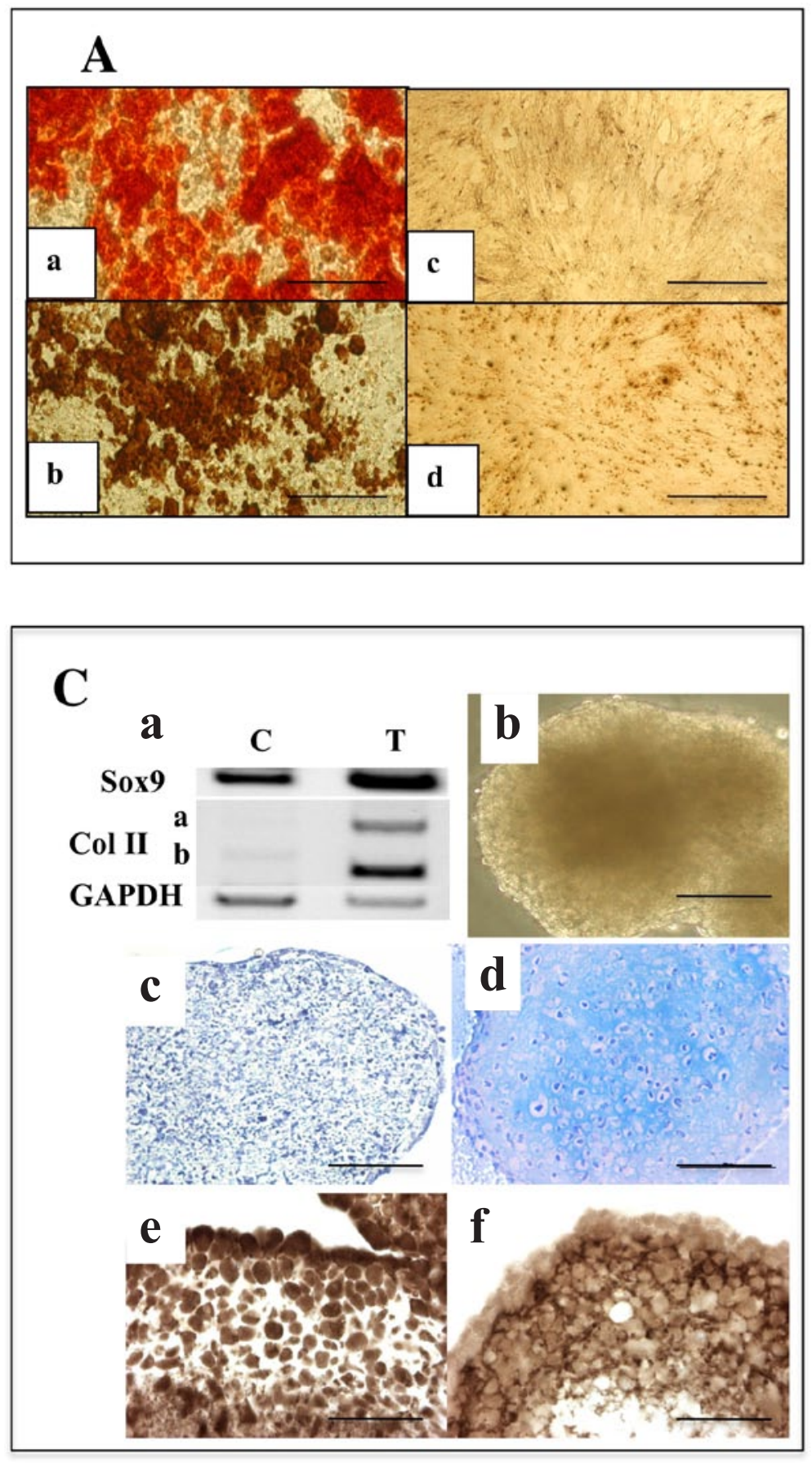
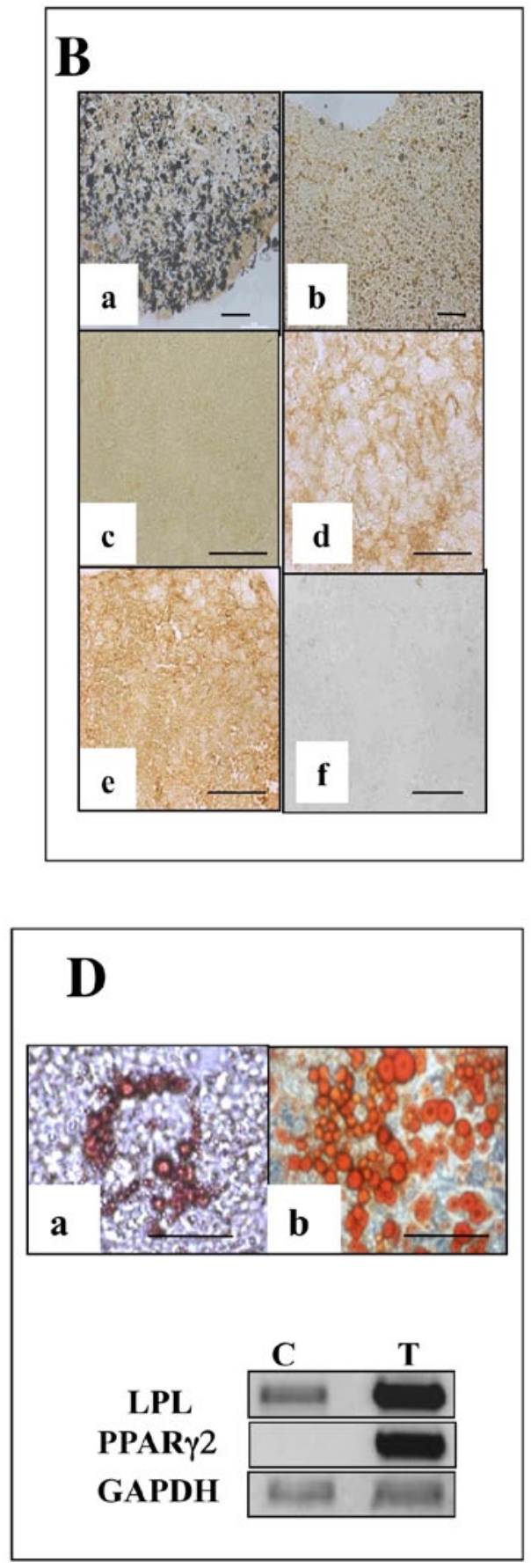

Fig. 1. Distinct in vitro differentiation potentials of pulpal progenitors. (A) Mineralisation potential of A4, H8 and C5 clones. Staining with Alizarin red (a) and Von Kossa reaction (b) on A4 cells treated for 2 weeks with $\beta$ GP/ AA/DEX. Absence of von Kossa staining in H8 (c) and C5 (d). Bar: $100 \mu \mathrm{m}$. (B) Osteogenic differentiation in A4 cell nodules. (a) Von Kossa reaction on sections of A4 aggregates treated for 15 days with AA/ $\beta$ GP reveals matrix mineralisation; (b) untreated controls. (c-f) Immunocytochemical staining on aggregate sections: treated aggregates are positive for BSP (e) and Col I (d) but negative for DSP (f). Untreated control aggregates are not labelled for Col I (c). Bar: $200 \mu \mathrm{m}$. (C) Chondrogenic differentiation in A4 cell nodules. (a) RT-PCR analysis shows an activation of Sox 9 and Col II isoform B transcripts in differentiated aggregates (T) as compared to non-treated controls (C). GAPDH was used as an internal control. (b) A4 aggregates treated for 10 days in chondrogenic medium (d) Alcian blue staining on sections of aggregates treated for 10 days with DEX/TGF $\beta 1$ reveals the presence of aggrecan in the ECM; (c) untreated controls. Immunocytochemical staining on treated aggregate sections reveals Sox9 in the nuclei (e) and Col II in the ECM (f). Bar: $50 \mu \mathrm{m}$. (D) Adipogenic differentiation in A4 cells. RT-PCR analysis reveals an activation of LPL and PPAR 2 expression in cells treated for 2 weeks with IBMX/Indomethacin/Insulin/DEX (T) as compared to untreated controls (C). GAPDH was used as an internal control. Oil red O staining of A4 (a) or MOpK4 bone marrow (b) progenitors. Bar: $100 \mu \mathrm{m}$. 

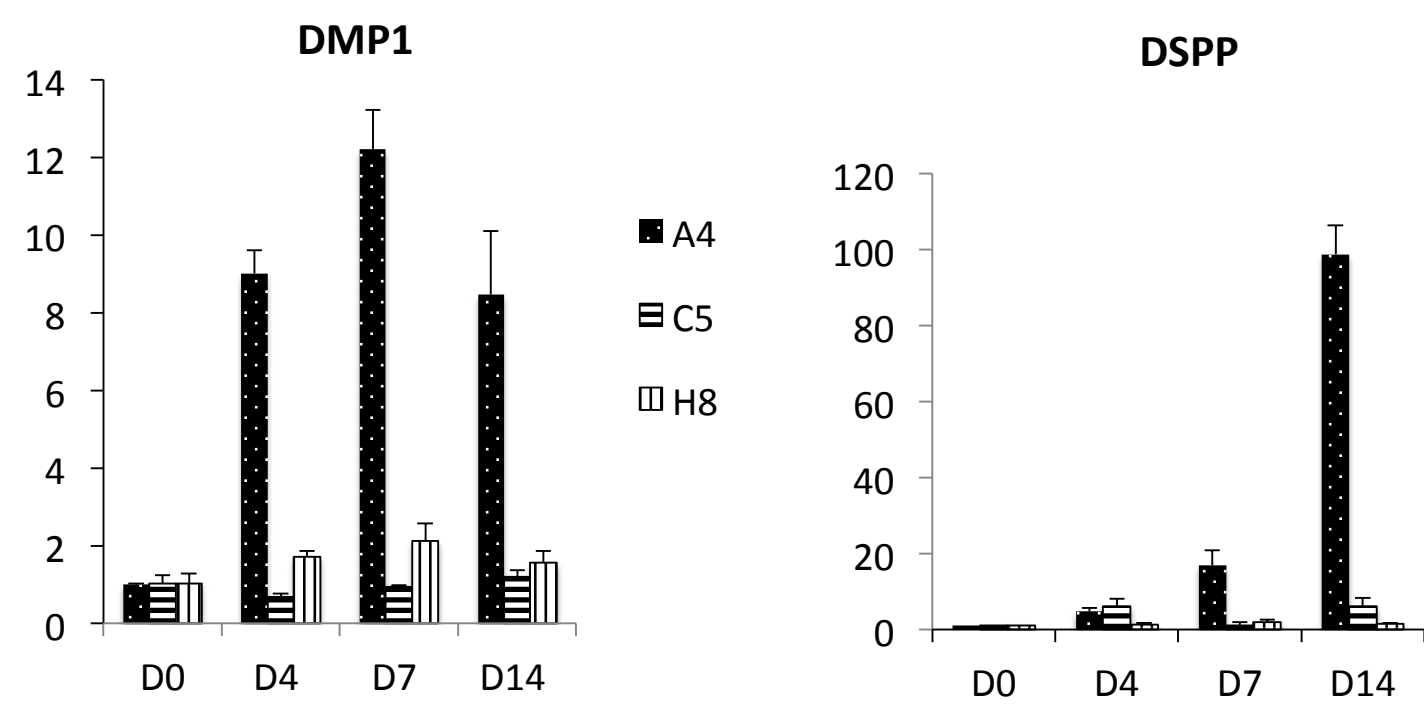

Fig. 2. DMP1 and DSPP transcripts expression of A4, C5 and H8 cells cultured in the presence of AA/ $\beta$ GP/DEX. The A4, C5 and H8 cells were treated by AA/ $\beta$ GP/DEX for $0,4,7$ or 14 days. Transcript levels were normalised to the TBP control and expressed relative to those of untreated D0 cells. The values are mean $+/-\operatorname{SEM}(n=3)$.

were negative for Alcian blue staining and did not exhibit any significant labelling for Sox9 nor deposit a type II collagen matrix (Fig. 1Cb and data not shown). Accordingly, RT-PCR analyses performed in parallel, revealed an activation of the transcripts of Sox 9 and of type II collagen isoform II B in the induced nodules as compared to the untreated ones (Fig. 1C).

Finally, the ability of the 3 pulpal clones to differentiate along the adipogenic program was evaluated by exposing monolayer cultures to the classical inducers of in vitro adipogenic differentiation. After 15 days, A4 cells started to form fat droplets stained by Oil red O (Fig. 1Da). The frequency of conversion towards adipocyte-like cells increased over time ( $>40 \%$ at 3 weeks), but remained inferior to that observed in mesenchymal progenitors derived from adult bone marrow (Fig. 1Db). As monitored by RT-PCR analysis, induced A4 cells expressed high levels of transcripts encoding two adipocyte markers, the peroxisome proliferator-activated receptor $\gamma 2$ (PPAR $\gamma 2)$ and the lipoprotein lipase (LPL) whereas these mRNAs remained barely detectable in untreated confluent cultures (Fig. 1D). No phenotypic conversion was observed upon induction of the $\mathrm{C} 5$ and $\mathrm{H} 8$ clones as inferred by the absence of transcriptional activation of LPL or PPAR $\gamma 2$ and of Oil red O positive cells, even after 4 weeks of treatment (data not shown).

\section{The three cell lines derived from dental pulp induce osteodentin formation after implantation in the incisor pulp}

To assess the ability of the pulpal cell lines to participate in dentinogenesis in vivo, A4, H8 or C5 cells were implanted in the mouse lower incisor pulp. Ten days after implantation, in the sham control sections, in reaction to the surgical pulp exposure, palleal dentin formation was observed (Fig. 3Aa) in restricted areas tracing the impact of the initial site of perforation. In contrast, histological staining revealed that an abundant osteodentin formation was reproducibly visualised in the central zone of the pulp at proximity of the engrafted A4, $\mathrm{H} 8$ or $\mathrm{C} 5$ cells. The reparative dentin appeared as a typical osteodentin with cells embedded within the matrix in lacunae (Fig. 3Ab,c,d) as observed after the treatment of a deep carious lesion in the molar (Goldberg and Smith, 2004). Consistent with these histological observations, immunohistochemical analysis on the corresponding incisor sections revealed that BSP was associated to this osteodentin. In contrast DSP was virtually undetectable in pulpal cells while, as expected, the thin odontoblastic processes were positively stained in the pre-existing dentin (Fig. 3Ae,f). This is in contrast to pluripotent ES cells which did not lead to any dentin formation (Fig. 3Ag) but generate an inflammatory tumour-like tissue, once implanted in the pulp in the same conditions.

Since the immunohistochemical analyses must be performed on demineralised tissue, 3D analyses by X-ray microscanner of the hemimandibles were performed on the incisors 10 days after implantation to determine whether the newly formed tissue was mineralised. As expected for dentin, pulps of the sham controls appeared radiolucent (Fig. 3Ba). In contrast, those implanted with the progenitor cells A4, C5 and H8, displayed the radio-opacity expected for an osteodentin (Fig. 3Bb,c,d).

The pulpal A4 clone is capable of in vivo reparative bone formation after implantation in a calvaria critical-size defect

To determine whether the A4 clone, which behaved as a multipotent mesoblastic cell in vitro, was able to differentiate towards non-dental phenotypes in vivo, the cells mixed with HA/TCP were transplanted in a criticalsized defect prepared in the mouse calvaria. As a positive control, the bone marrow-derived mesenchymal cell line, MOpK4, was implanted in parallel experiments, stromal progenitor cells displaying a well-characterised bone repair potential in this context (Krebsbach et al., 1998). Three 
A

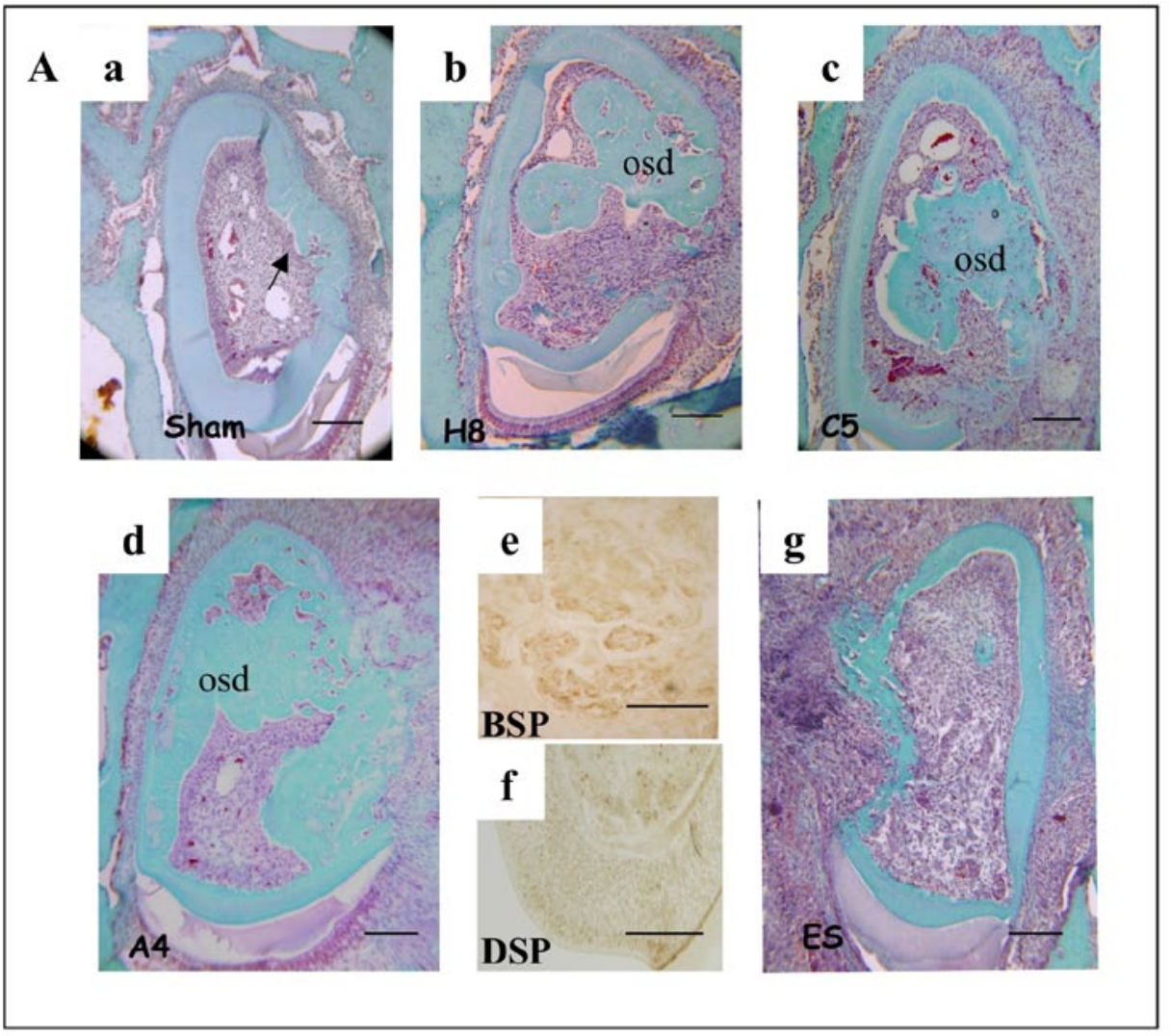

B
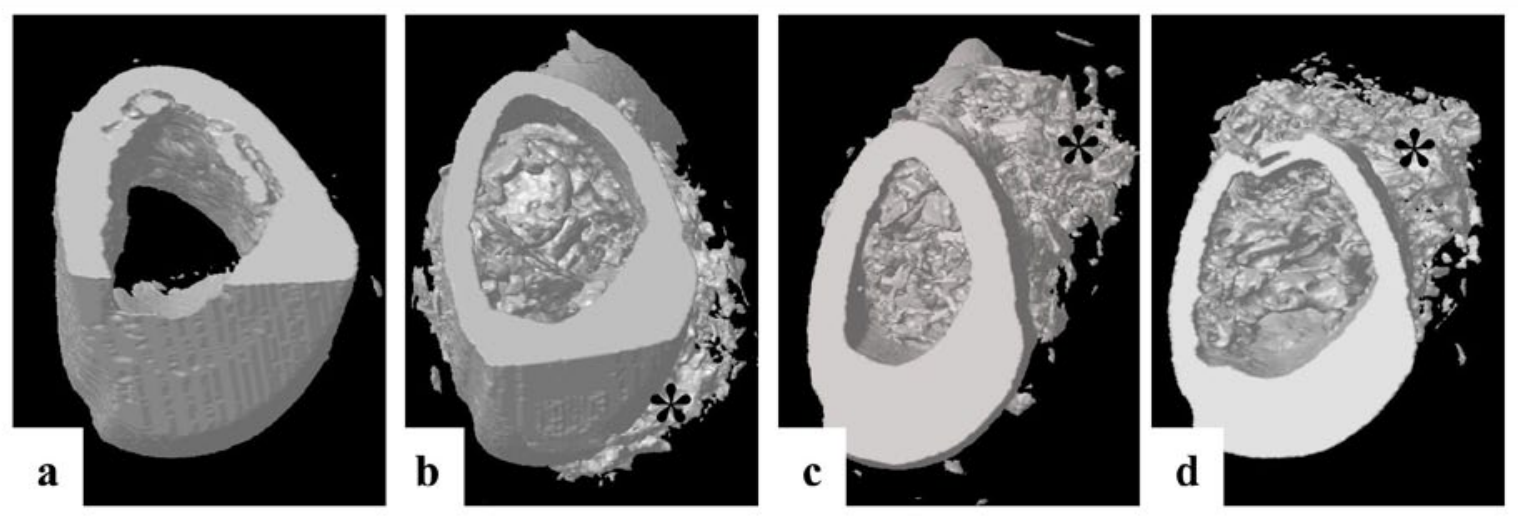

Fig. 3. In vivo dentin formation, 10 days after implantation of the dental pulp progenitors into a mouse incisor. (A) Masson's trichrome staining of incisor sagittal sections shows a limited reactive palleal dentin formation in sham pulp (arrow) (a), and an abundant formation of an osteodentin-like neodentin (osd) within the pulp implanted with H8 (b), C5 (c) or A4 (d) cells. Formation of a tumour-like tissue is observed upon implantation of ES cells (g). (e, f) Immunocytochemical staining on incisor sagittal sections reveals the presence of BSP (e) and the absence of DSP (f). Bar: $200 \mu \mathrm{m}$. (B) Micro-scanner analyses show the presence of mineralised structures within the pulp after implantation of A4 (b), H8 (c) or C5 cells (d) but not in the sham pulps (a). Note that the (*) in b, c and d corresponds to residual bone material not removed during preparation of the samples.

months after implantation, direct observations indicated an absence of tissue healing in the control group transplanted only with HA/TCP (Fig. 4Aa). In contrast, calvaria implanted with the A4-HA/TCP or MOpK4-HA/TCP cells displayed bone formation involving, in both cases, about $70 \%$ of the defect (Fig. 4Ac and e, respectively). Haematoxylin-eosin staining of implanted calvaria sections revealed important new bone formation, deposited in continuity with the adjacent mouse calvaria surrounding the initial defect (Fig. 4Ad,f). Such a bone formation was not observed in the HA/TCP control group (Fig. 4Ab) nor in calvaria implanted with $\mathrm{C} 5$ or $\mathrm{H} 8$ cells (Fig. 4Ag and h, respectively). Of note, immunohistochemical analyses of A4 and MOpK4 implanted calvaria sections showed that the newly formed tissue was positive for BSP (Fig. 4Ba and b) and negative for DSP (Fig. 4Bc and d). 

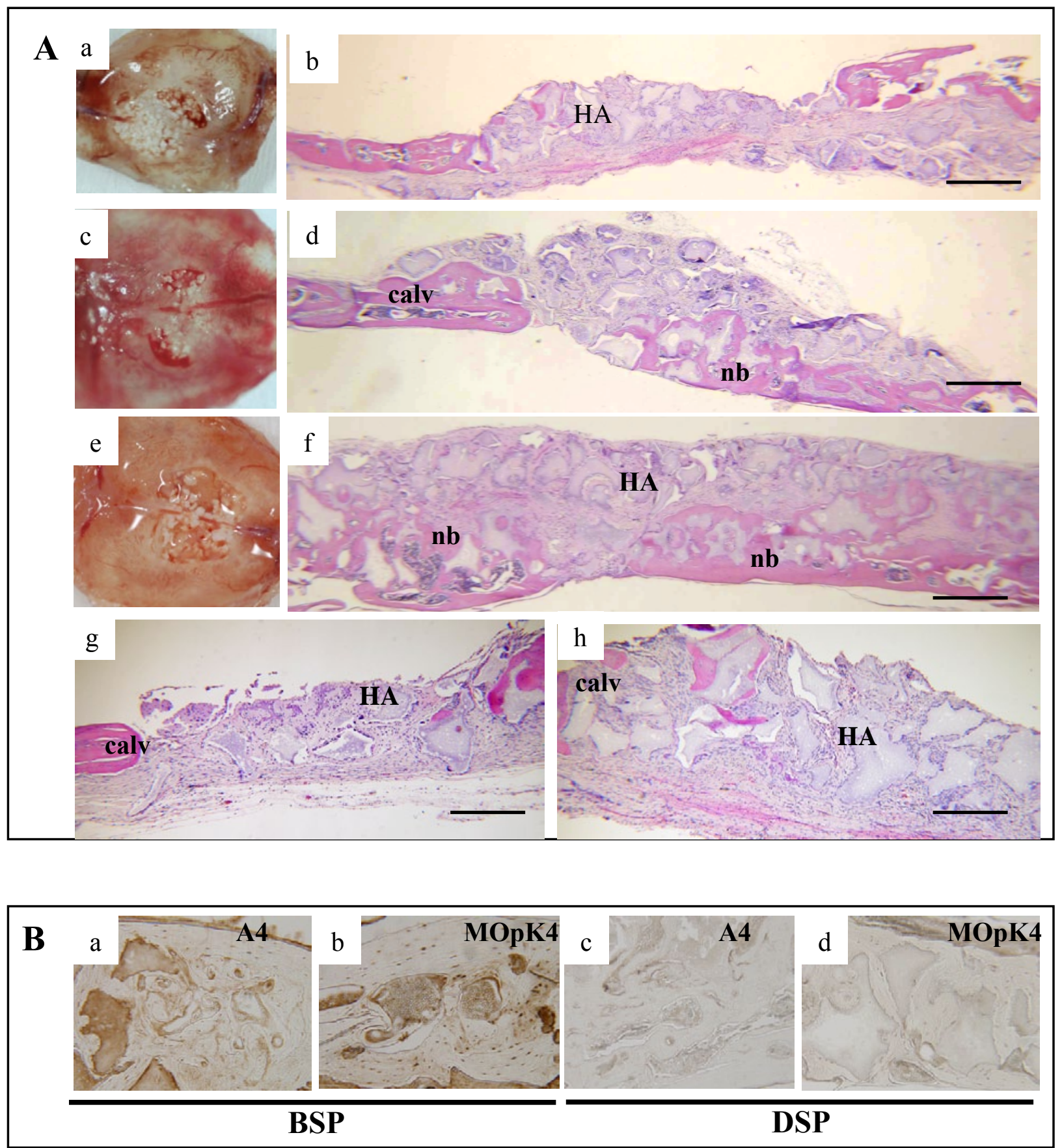

Fig. 4. Bone formation, 3 months after implantation of progenitors in critical-size defects of mouse calvaria. (A) New bone formation is observed after implantation of HA/TCP mixed with A4 (c, d) or MOpK4 cells (e, f) but not with HA/TCP alone $(\mathbf{a}, \mathbf{b})$ or with the C5 or H8 cells $(\mathbf{g}, \mathbf{h}$, respectively). Direct view of the implanted calvaria (a, $\mathbf{c}, \mathbf{e})$ and HE staining of calvaria sections $(\mathbf{b}, \mathbf{d}, \mathbf{f}, \mathbf{g}$ and $\mathbf{h})(\mathrm{nb}=$ newly formed bone; HA = hydroxyapatite; calv = calvaria). (B) Immunostaining of the newly formed tissue reveals the presence of respectively BSP (a, b) and the absence of DSP $(\mathbf{c}, \mathbf{d})$ in A4+HA/TCP and MOpK4+HA/TCP implanted calvaria sections, respectively. Bar: $500 \mu \mathrm{m}$.

Transplanted cell progenies are present in areas of dentin formation and calvaria repair

We next sought to evaluate the presence of progenitorderived differentiating cells in the areas of osteodentin formation or calvaria repair. Since the three cell lines, A4, $\mathrm{C} 5$ and $\mathrm{H} 8$, derived from transgenic mice expressing the early region of SV40 under the E1A promoter of adenovirus, the large T antigen of SV40 can be used as a flag to detect implanted cell progenies. However, the very low level of large $\mathrm{T}$ antigen expression precluded the direct detection of the $\mathrm{T}$ protein by immunohistochemistry within demineralised tissues. An alternative was to trace the presence of the corresponding transgene in the newly formed tissues. Areas of dentin formation (10 days post-implantation) or calvaria repair ( 3 months postimplantation) were isolated from implanted tissues by laser microdissection and pressure catapulting (Fig. 5Aa,b, and Fig. 5Ac,d, respectively). Non-implanted tissue fragments, adjacent to newly formed tissues (dentin or bone) were taken as controls. When PCR analyses were performed 


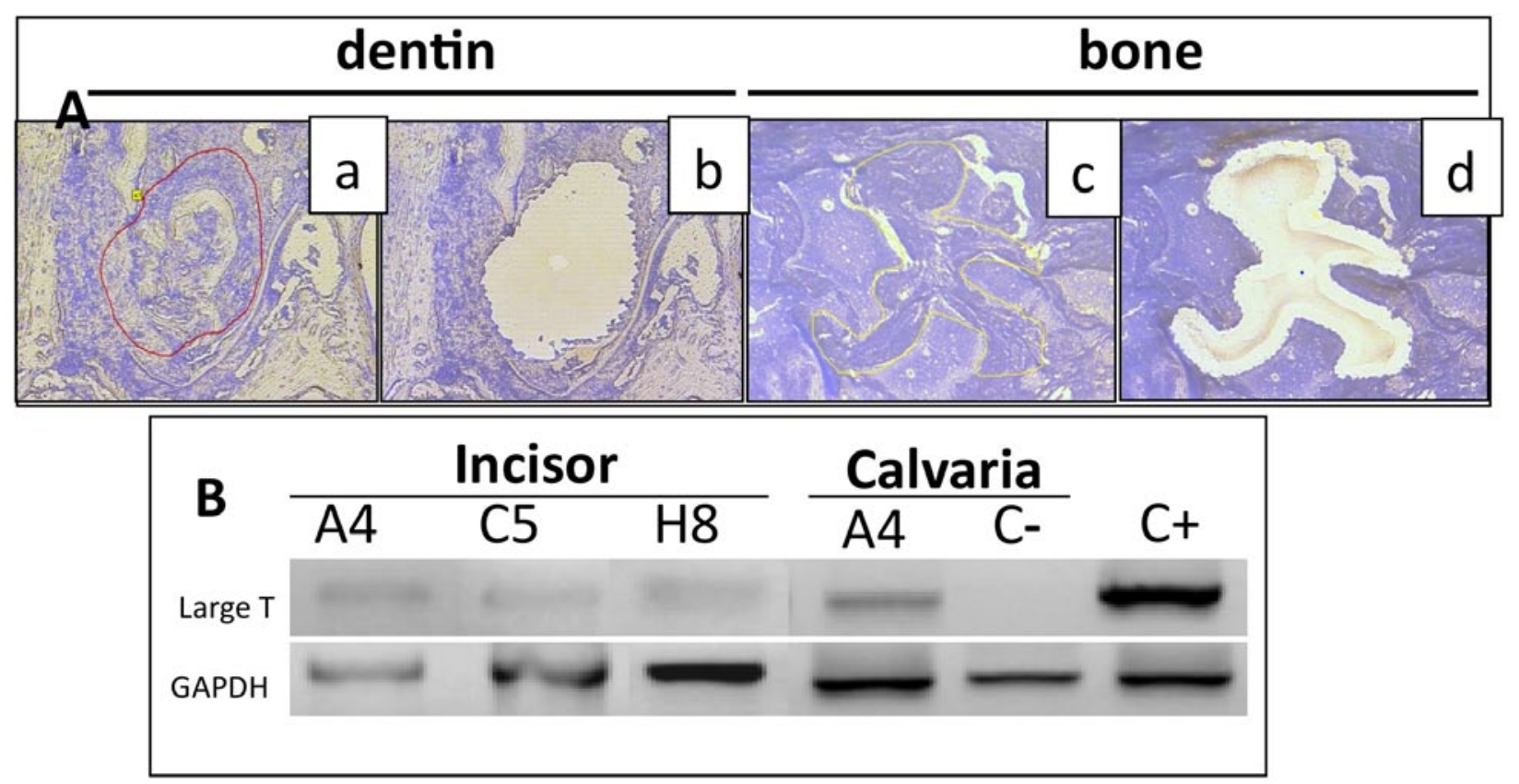

Fig. 5. Presence of transplanted cell progenies in areas of neo-dentin or bone formation. (A) Representative samples of newly formed dentin $(\mathbf{a}, \mathbf{b})$ or bone $(\mathbf{c}, \mathbf{d})$ before $(\mathbf{a}, \mathbf{c})$ or after $(\mathbf{b}, \mathbf{d})$ laser microdissection from sections of incisor or calvaria implanted with A4 cells. (B) PCR analysis of DNA extracted from micro-dissected tissues. The T antigen gene is detected in all zones of newly formed dentin or bone but not in control areas. C(-): DNA extracted from nonimplanted tissue samples. $\mathrm{C}(+)$ : DNA extracted from $\mathrm{pK} 4$ transgenic mouse tail.

on the DNA extracted from these samples, the transgene was detected in all extracts originating from reparative osteodentin or bone formation areas, while it was absent in the controls (Fig. 5B).

The cell surface molecule CD90 is differentially expressed by the pulpal progenitors according to their differentiation potentials

Identification of markers signing dental progenitors would greatly facilitate the localisation and isolation of these "stem" cells within the pulp. The availability of independent cell lines that all belong to the odontogenic lineage, but differ in their differentiation potential, led us to search whether cell surface molecules may be differentially expressed by these pulp-derived progenitors.

To this end, we analysed by flow cytometry the pattern of expression of a set of cell surface molecules classically used to characterise cells of haematopoietic, endothelial or mesenchymal origin. As shown in Fig. 6A,B, for the 3 pulpal clones, a large number of cells (more than $75 \%$ ) expressed Sca-1, CD44, 3G5, CD146, CD34. In addition, the cells also expressed $\alpha$ smooth muscle actin ( $\alpha$ SMA). In contrast, no significant CD45, CD117 (c-kit), CD31 or CD105 expression could be detected. The only clearly overt differential expression between the clones, was for CD90. C5 and H8 cells were both positive for this marker, whereas A4 cells were totally negative (Fig. 6B). Thus, CD90 might constitute a cell surface marker allowing the discrimination between different types of pulpal progenitors. This hypothesis was further evaluated by assessing the status of CD90 expression in three other pulpal cell lines G10, G7 and A11, isolated in parallel with the A4, C5 and H8 clones. Indeed, FACS analysis revealed that they also presented differential expression of CD90: $80 \%$ of G10 cells were positive, while only 10 $\%$ of G7 cells and less than $5 \%$ of A11 cells expressed it (Table 2). The capacity for osteogenic, chondrogenic and adipogenic differentiation of these clones was then explored. This analysis revealed that the G7 and A11, but not G10, were both able to form 3D aggregates and to engage in osteogenic differentiation as revealed by their progressive mineralisation beginning after 5 days in the presence of osteogenic medium. Only A11 was readily able to undertake adipogenic differentiation (Fig. 7A,B). Furthermore, similarly to A4, this clone could be recruited towards the chondrogenic lineage, displaying its hallmarks, expression of aggrecan and isoform B of Col II transcripts as soon as 7 days after induction (Fig. 7C). In contrast, G10 could not form 3D-aggregates, did not mineralised even in 2D-cultures nor formed lipid droplet even after a 3 weeks in the presence of inducers of the corresponding programs (data not shown).

\section{Discussion}

The human dental pulp contains a sub-population of cells endowed with a differentiation potential towards dental and non-dental cell lineages such as osteoblastic, chondrogenic, adipogenic, myogenic, endothelial, neuronal or melanocyte lineages, following appropriate induction (Gronthos et al., 2000; Zhang et al., 2006; d'Aquino et al., 2007; Yamazaki et al., 2007; Arthur 2008; Stevens et al., 2008; Paino et al., 2010). Upon in vivo implantation they are capable of 
A
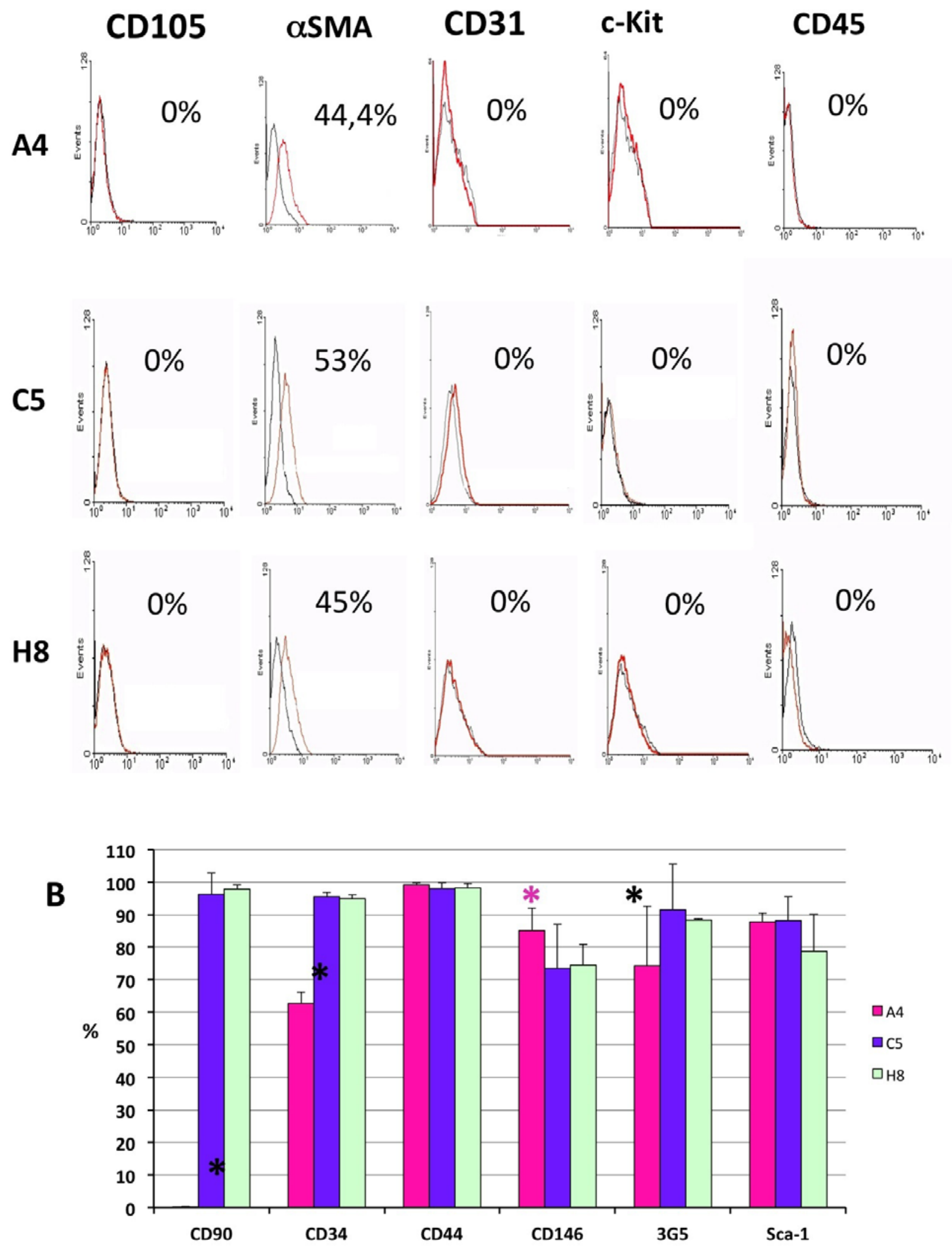

Fig. 6. Flow cytometric analysis of A4, C5 and H8 dental pulp progenitors. (A) Histogram plots. All clones were stained with the assigned antibodies conjugated to FITC or PE and analysed with a FACScalibur cytometer and CellQuest software. Histograms show the control IgG isotype staining profile (black line) versus the specific antibodies staining profile (red line). Representative data from 3 independent experiments. (B) Histogram representation of the mean expression and standard deviation of representative MSC markers at the surface of the pulpal clones. Bar = standard deviation. $\left(^{*}\right)$ indicates a significant difference in expression between the A4 clone and H8 and C5 ( $p<0.1$ $\%$, Mann-Whitney test). 

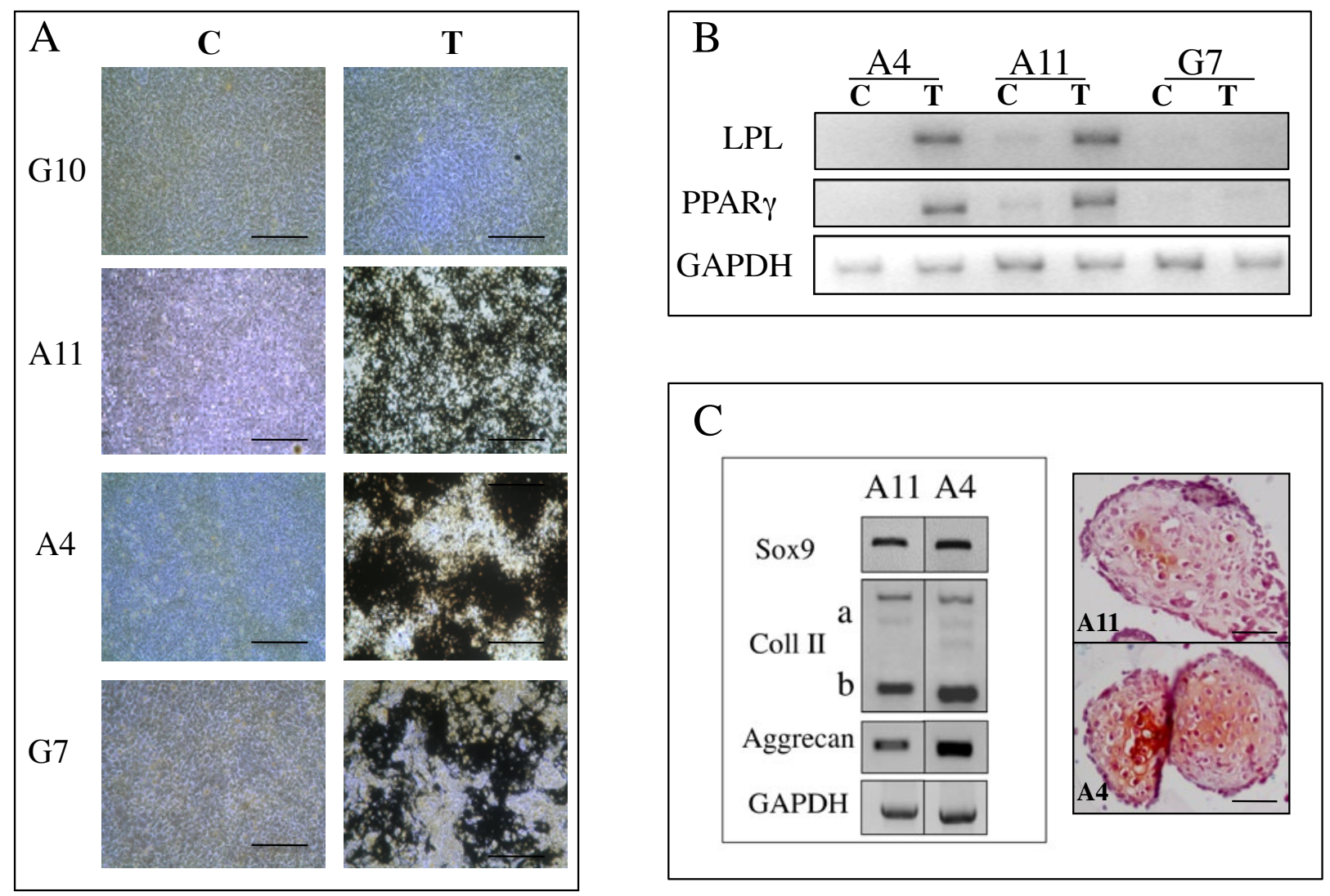

Fig. 7. (A) Mineralisation potential of the G10, A11, A4 and G7 clonal cells. Von Kossa staining of G10, A11, A4 and $\mathrm{G} 7$ cells cultured as monolayers and treated for 10 days in mineralisation medium $(\mathrm{T})$, as compared to untreated control cultures (C) show the formation of mineralisation nodules in A11, A4 and G7 but not in G10. Bar: $100 \mu \mathrm{m}$. (B) Adipogenic potential of the A11 and G7 as compared to A4 cells. RT-PCR analysis reveals an activation of LPL and PPAR $\gamma 2$ expression in A11 as in A4 but not in G7 cells treated for 2 weeks in adipogenic medium (T) as compared to untreated controls (C). GAPDH was used as an internal control. (C) Chondrogenic potential of A11 as compared to A4 cells. RT-PCR analysis of A11 and A4 aggregates treated for 7 days in chondrogenic medium shows the expression of Sox9, type II collagen isoform IIB and aggrecan. A11 and A4 aggregate sections stained with Safranin O reveals aggrecan in the extracellular matrix. Bar: $50 \mu \mathrm{m}$.

forming a dentin-like or a bone-like tissue. Pulpal stem cells appear thus to share common properties with the mesenchymal progenitors of the bone marrow (Shi et al., 2001) and could constitute an alternative source for adult MSCs, without the shortcomings, morbidity and low cell number upon harvest, observed with the MSCs from the bone marrow. Furthermore, their neural crest origin (Chai et al., 2000) could give them characteristics potentially interesting for cell therapies of the cranial sphere. However, a better knowledge of the biology of these dental stem cell populations is a prerequisite to forecasting the extent of their efficiency for regenerative medicine. In particular, the question of the origin of their "multipotency" has never been completely clarified since all the data available were obtained with uncloned cell populations. The distinct phenotypes observed could therefore result from the presence of multipotent precursors, as it is the case in the bone marrow stroma (Pittenger et al., 1999), but also from the co-existence of various precursors displaying different restricted potentials, or both. Characterising different progenitor populations in the pulp is of major importance in the context of cell therapy development since the type of progenitor used and its differentiation stage may prove
Table 2. Flow cytometry analysis of markers on the pulpal clones.

\begin{tabular}{lccc} 
& A11 & G7 & G10 \\
\hline CD45 & - & - & - \\
CD117 (c-kit) & - & - & - \\
CD90 (Thy-1) & - & + & +++ \\
CD31 & - & - & - \\
\hline
\end{tabular}

Samples were scored as (-): if less than $2 \%$, as $(+)$ : if less than $10 \%$, as $(+++)$ : if more than $75 \%$ of the cells express the surface marker.

essential for a therapeutic benefit in a given context. Using clonal cells is thus determinative to answer this question. Furthermore, the use of mouse pulp progenitor cells allows for their in vivo evaluation in the mouse animal model within an integrated context, without the need of immunodepression treatments, which might affect the host response as well as the differentiation behaviour of the implanted cells.

Among the pulp-derived clones, the A4 cell line has properties of a typical mesodermal multipotent stem cell with capacity of both maintaining a stable phenotype in 
absence of induction and of producing a progeny whose choice of fate is driven by the nature of extracellular signals. In response to inducing signals, the A4 cell line can undergo unidirectional differentiation along either odonto/ osteogenic, chondrogenic or adipogenic lineage. These in vitro properties provide strong evidence that in the dental pulp, some progenitors have truly multipotent mesoblastic stem cells features.

In contrast, other pulpal clones present a more restricted potential. The $\mathrm{C} 5$ and $\mathrm{H} 8$ clones behave as precursors univocally committed to the odontoblastic lineage, since all attempts to recruit them towards osteogenic, chondrogenic or adipogenic differentiation remained unsuccessful.

These data obtained with single-cell derived clones indicate that distinct subsets of progenitors coexist within the dental pulp. Stem cell populations are essential for lifelong maintenance of tooth functions and homeostasis. It is conceivable that, as in the bone marrow (Muraglia et al., 2000; Sloan and Smith, 2007) the stem/progenitor cell system of dental pulp is hierarchically organised with multipotent precursor cells corresponding to primitive ectomesenchymal stem cells progressively giving rise to committed progenitors that adopt a restricted odontoblastic fate, and to stromal cells. Our combined results on the A4, C5, H8, as well as A11, G7 and G10 clones appear to support this view.

In the tooth, location and elements of the presumptive niche(s) providing the physiological environment supporting pulpal precursor cells homeostatic self-renewal and odontogenic differentiation are still poorly understood. It is, in particular, essential to understand how transplanted pulpal precursors might interpret signals within the in vivo environment, for cell therapy to be envisioned as a possible treatment for dentin lesions. As shown by histological and $\mathrm{x}$-ray microscanner analyses, implantation of pulp-derived progenitors in the mouse incisor pulp reproducibly leads to the formation of abundant osteodentin-like structure in the central part of the pulp: the radio-opacity of the mineral structure resembles an osteodentin, less compact and mineralised than the orthodentin, possibly because of a defective phosphorylation of the SIBLINGs as documented (MacDougall et al., 1992). Such an osteodentin is observed upon ectopic implantation of dental pulp tissue (Braut et $a l ., 2003)$ and in vivo, in case of dentin repair following mild dentinal-lesions. Of note, despite their cell-intrinsic differences revealed by in vitro studies, each of the three precursor clones similarly responded to the pulpal environment by forming osteodentin. Since care was taken to drill the dentin and implant the cells in the same limited site, conceivably, each clone integrates a permissive environment allowing its survival and differentiation. This contrasts with the mouse ES cells that are unable to stimulate an osteodentin formation when similarly implanted. These observations further suggest that the pulpal progenitors are primed or "intrinsically" endowed with an ability to respond to the pulpal microenvironment.

The important question raised at this point was whether the implanted cells were directly responsible for the dentin formation or alternatively, whether they produced a "signal" mobilising resident progenitors to differentiate. This last hypothesis has indeed been suggested to explain, in some cases, the "plasticity" of bone marrow MSCs (Iso et al., 2007; Prockop, 2007). Laser microdissection data combined with PCR analysis revealed the presence of implanted cell progenies within the zone of newly formed dentin suggesting, that 10 days after the pulp exposure, at least some of these cells are directly involved in the reparative tissue formation. This does not preclude an involvement of host progenitors recruited on the lesion site that might also be involved in the osteodentin synthesis.

Human dental pulp stem cell populations isolated from decidual teeth (SHED) have been shown to contribute to repair of a critical-size defect of the calvaria, formed in immunodeficient mice (Seo et al., 2008). In line with these observations, our implantation in this classical model for bone repair studies of A4 multipotent clonal cells led to healing of the defect with a similar efficiency as a bonemarrow stromal cell line used as positive control (Mankani et al., 2006). In contrast, in the same conditions, the $\mathrm{C} 5$ and $\mathrm{H} 8$ restricted progenitors were unable to promote new bone formation. As with implantation in incisors, laser microdissection followed by PCR analysis reveals the presence of the large $T$ antigen gene in cells of the repaired zones, demonstrating that $\mathrm{A} 4$ cell progenies are still present within the new bone after 3 months. This strongly suggests that in a physiological, non immuno-suppressed context, the clonal A4 cells directly participated in the repair process.

Altogether, these observations support the view that the sites of implantation used, pulp or calvaria, provide the proper developmental clues to regulate the behaviour of a multipotent progenitor like A4 in contrast to more "restricted" pulp progenitors such as $\mathrm{C} 5$ or $\mathrm{H} 8$.

Identification of markers allowing the localisation and isolation of specific progenitor cells is central for the development of cell therapies. Up to now, no typical marker has been specifically assigned to adult mesenchymal stem cells. Their characterisation or isolation is based on the expression of a combination of cell surface proteins (Dominici et al., 2006). As described for human dental pulp stem cells, the 3 mouse dental pulp clones express "classical" cell surface markers of progenitor cells from mesenchymal origin (Sca-1, CD44,), together with "pericyte" markers such as $\alpha$ SMA, CD146 and 3G5 and, as expected, no CD45 or CD31 which target haematopoietic cells (Gronthos et al., 2002; Iohara et al., 2006). CD105, a typical marker of human MSCs (Dominici et al., 2006), is not expressed by our clones. Since we found it expressed in freshly isolated P5 mouse dental pulp cells (our unpublished observations) and not on cultured MOPK4 MSCs isolated from adult bone marrow, one hypothesis is that this lack of expression is related to the time in culture. In addition, the mouse clones express CD34, with some variations in the percentage of expressing cells. CD34 is associated with a cell surface antigen expressed by the most primitive stromal stem cells, gradually lost after lineage committed progenitors differentiation (Barclay et al., 1988). In human and mouse dental pulp cells, CD34 expression has also been shown to vary (Gronthos et al., 2000; Laino et al., 2005), probably reflecting a rapid down-regulation of this marker upon culture and/or differentiation. In the mouse, a variable expression of this molecule has been reported 
in mesenchymal stromal cells, depending on the strain (Meirelles Lda and Nardi, 2003; Sun et al., 2003; Peister et al., 2004; Planat-Benard et al., 2004).

Interestingly, CD90, considered as a typical stromal cell-associated molecule (Pittenger et al., 1999) expressed in bone marrow mesenchymal cells, showed a differential expression in the pulpal progenitor clones. While it was found expressed at the surface of the $\mathrm{C} 5$ and $\mathrm{H} 8$ monopotent progenitor cells, it was undetectable in the A4 multipotent clone. Analysis of 3 additional pulpal clones further supports a correlation between CD90 expression and a pulpal progenitor potential for differentiation. Indeed, A11, which, as A4, virtually does not express CD90 (less than $5 \%$ of the cells positive for CD90), is able to undertake odonto/osteogenic, adipogenic and chondrogenic differentiation after appropriate induction and thus corresponds at least, as A4, to a tripotent progenitor. In contrast G7, which contains only $10 \%$ of CD90 expressing cells, is able to respond to osteogenic but not to adipogenic induction. In line with this, G10 cells, all positive for CD90 as $\mathrm{H} 8$ and C5 cells, are totally unresponsive to our osteogenic or adipogenic induction conditions. A differentiation stage-dependent expression of CD90 has been previously described in mouse osteoblast precursors, CD90 expression being absent in the early progenitors and becoming activated in the first stages of differentiation (Chen et al., 1999). In the young mouse dental pulp (P5-7), a subpopulation of Sca1+/CD90-/ low progenitors can be evidenced immediately after pulp culture establishment. This population presents an increase in proliferation potential as compared to the unselected pulp cells (our unpublished results). Interestingly, a Stro1+/ CD90-/low subpopulation is also detected in human pulp cells shortly after tissue dissociation and culture establishment (our unpublished results). Whether CD90 is a cell surface marker that could be used to discriminate different types of dental pulp progenitors will have now to be further investigated by comparing the differentiation efficiency of the CD90- and CD90+ progenitor cells in vitro and in vivo.

\section{Conclusion}

Unravelling the nature and properties of the progenitor/ stem cell populations in the pulp is of paramount importance for future design of strategies for dental repair and other cranio-facial tissue engineering. The numerous studies now available describing "DPSCs" that slightly differ in their potentials suggest the presence of different types of progenitors in the pulp. An apparent "identical" progenitor phenotype, the multipotent DSPCs, may recover a series of cells at different degrees of "maturation", likely reflecting a progenitor hierarchy as observed in the bone marrow (Muraglia et al., 2000) and our data support this hypothesis. Some of these progenitor cells might therefore be more efficient than others in performing tissue repair and their specific "fishing out" might considerably improve the accuracy and reproducibility of the therapeutic processes.

Because the mouse dental pulp clones express a set of cell surface molecules similar to that of human dental pulp stem cells, they constitute valuable tools to phenotypically define distinct types of cell progenitors, based on the sorting of subpopulations expressing different levels of cell surface molecules such as CD90 which can then be evaluated for their repair potential in dental pulp but also other cranio-facial tissue lesions.

\section{Acknowledgments}

S. Lacerda-Pinheiro was supported by Coordenação de Aperfeiçoamento de Pessoal de Nivel Superior (CAPES), Brazil, Y. Harichane by IFRO, S. Dimitrova-Nakov by the DIM Stem Pole Ile de France and A.Baudry by a CDD Junior Inserm. We warmly thank Dominique Septier and Marie Noëlle Monier for their skilful technical assistance in histology and cell analysis. We are grateful to Dr M. Corvol for her help with cartilage histology. This research was partially supported by grants of the CNRS, the Fondation de l'Avenir, by l'Institut Français pour la Recherche Odontologique (IFRO) and by Inserm "Somatic Stem Cells Research grant" CS0307.

\section{References}

Adam C, Llorens A, Baroukh B, Cherruau M, Saffar JL (2000) Effects of capsaicin-induced sensory denervation on osteoclastic resorption in adult rats. Exp Physiol 85: 62-66.

Arthur A, Rychkov G, Shi S, Koblar SA, Gronthos S (2008) Adult human dental pulp stem cells differentiate toward functionally active neurons under appropriate environmental cues. Stem Cells 26: 1787-1795.

Ballock RT, Reddi AH (1994) Thyroxine is the serum factor that regulates morphogenesis of columnar cartilage from isolated chondrocytes in chemically defined medium. J Cell Biol 126: 1311-1318.

Barclay AN, Jackson DI, Willis AC, Williams AF (1988) The leukocyte-common antigen (L-CA) family. Adv Exp Med Biol 237: 3-7.

Braut A, Kollar EJ, Mina M (2003) Analysis of the odontogenic and osteogenic potentials of dental pulp in vivo using a Col1a1-2.3-GFP transgene. Int J Dev Biol 47: 281-292.

Chai Y, Jiang X, Ito Y, Bringas P Jr, Han J, Rowitch DH, Soriano P, McMahon AP, Sucov HM. (2000) Fate of the mammalian cranial neural crest during tooth and mandibular morphogenesis. Development 127: 1671-1679.

Chen XD, Qian HY, Neff L, Satomura K, Horowitz MC (1999) Thy-1 antigen expression by cells in the osteoblast lineage. J Bone Miner Res 14: 362-375.

d'Aquino R, Graziano A, Sampaolesi M, Laino G, Pirozzi G, De Rosa A, Papaccio G (2007) Human postnatal dental pulp cells co-differentiate into osteoblasts and endotheliocytes: a pivotal synergy leading to adult bone tissue formation. Cell Death Differ 14: 1162-1171.

Dominici M, Le Blanc K, Mueller I, Slaper-Cortenbach I, Marini F, Krause D, Deans R, Keating A, Prockop DJ, Horwitz E (2006) Minimal criteria for defining multipotent 
mesenchymal stromal cells. The International Society for Cellular Therapy position statement. Cytotherapy 8: 315 317.

Fitzgerald M, Chiego DJ Jr, Heys DR (1990) Autoradiographic analysis of odontoblast replacement following pulp exposure in primate teeth. Arch Oral Biol 35: 707-715.

Goldberg M, Smith AJ (2004) Cells and extracellular matrices of dentin and pulp: A biological basis for repair and tissue engineering. Crit Rev Oral Biol Med 15: 13-27.

Gronthos S, Mankani M, Brahim J, Robey PG, Shi S (2000) Postnatal human dental pulp stem cells (DPSCs) in vitro and in vivo. Proc Natl Acad Sci USA 97: 1362513630.

Gronthos S, Brahim J, Li W, Cherman N, Boyde A, DenBesten P, Robey PG, Shi S (2002) Stem cell properties of human dental pulp stem cells. J Dent Res 81: 531-535.

Huang GT, Gronthos S, Shi S (2009) Mesenchymal stem cells derived from dental tissues $v s$. those from other sources: their biology and role in regenerative medicine. J Dent Res 88: 792-806.

Iohara K, Zheng L, Ito M, Tomokiyo A, Matsushita K, Nakashima M (2006) Side population cells isolated from porcine dental pulp tissue with self-renewal and multipotency for dentinogenesis, chondrogenesis, adipogenesis, and neurogenesis. Stem Cells 24: 2493-2503.

Iso Y, Spees JL, Serrano C, Bakondi B, Pochampally R, Song YH, Sobel BE, Delafontaine P, Prockop DJ (2007) Multipotent human stromal cells improve cardiac function after myocardial infarction in mice without long-term engraftment. Biochem Biophys Res Commun 354: 700706.

Kerkis I, Kerkis A, Dozortsev D, Stukart-Parsons GC, Gomes Massironi SM, Pereira LV, Caplan AI, Cerruti HF (2006) Isolation and characterization of a population of immature dental pulp stem cells expressing OCT-4 and other embryonic stem cell markers. Cells Tissues Organs 184: 105-116.

Krebsbach PH, Mankani MH, Satomura K, Kuznetsov SA, Robey PG (1998) Repair of craniotomy defects using bone marrow stromal cells. Transplantation 66: 1272-1278.

Lacerda-Pinheiro S, Jegat N, Septier D, Priam F, Bonnefoix M, Bitard J, Kellermann O, Tompkins K, Veis A, Goldberg M, Poliard A (2006) Early in vivo and in vitro effects of amelogenin gene splice products on pulp cells. Eur J Oral Sci 114 Suppl 1: 232-238.

Lacerda-Pinheiro S, Marchadier A, Donas P, Septier D, Benhamou L, Kellerman O, Goldberg M, Poliard A (2008) An in vivo model for short-term evaluation of the implantation effects of biomolecules or stem cells in the dental pulp. Open Dent J 2: 67-72.

Laino G, d'Aquino R, Graziano A, Lanza V, Carinci F, Naro F, Pirozzi G, Papaccio G (2005) A new population of human adult dental pulp stem cells: a useful source of living autologous fibrous bone tissue (LAB). J Bone Miner Res 20: 1394-1402.

Laoide BM, Courty Y, Gastinne I, Thibaut C, Kellermann O, Rougeon F (1996) Immortalised mouse submandibular epithelial cell lines retain polarised structural and functional properties. J Cell Sci 109: 27892800 .
Locker M, Kellermann O, Boucquey M, Khun H, Huerre M, Poliard A (2004) Paracrine and autocrine signals promoting full chondrogenic differentiation of a mesoblastic cell line. J Bone Miner Res 19: 100-110.

MacDougall M, Slavkin HC, Zeichner-David M (1992) Characteristics of phosphorylated and non-phosphorylated dentine phosphoprotein. Biochem J 287: 651-655.

Mankani MH, Kuznetsov SA, Wolfe RM, Marshall GW, Robey PG (2006) In vivo bone formation by human bone marrow stromal cells: reconstruction of the mouse calvarium and mandible. Stem Cells 24: 2140-2149.

Meirelles Lda S, Nardi NB (2003) Murine marrowderived mesenchymal stem cell: isolation, in vitro expansion, and characterization. Br J Haematol 123: 702711.

Miura M, Gronthos S, Zhao M, Lu B, Fisher LW, Robey PG, Shi S (2003) SHED: stem cells from human exfoliated deciduous teeth. Proc Natl Acad Sci USA 100: 5807-5812.

Muraglia A, Cancedda R, Quarto R (2000) Clonal mesenchymal progenitors from human bone marrow differentiate in vitro according to a hierarchical model. J Cell Sci 113: 1161-1166.

Murray PE, Stanley HR, Matthews JB, Sloan AJ, Smith AJ (2002) Age-related odontometric changes of human teeth. Oral Surg Oral Med Oral Pathol Oral Radiol Endod 93: 474-482.

Nakashima M, Iohara K, Ishikawa M, Ito M, Tomokiyo A, Tanaka T, Akamine A (2004) Stimulation of reparative dentin formation by ex vivo gene therapy using dental pulp stem cells electrotransfected with growth/differentiation factor 11 (Gdf11). Hum Gene Ther 15: 1045-1053.

Paino F, Ricci G, De Rosa A, D’Acquino R, Laino L, Pirozzi G, Titino V, Papaccio G (2010) Ecto-mesenchymal stem cells from dental pulp are committed to differentiate into active melanocytes. Eur Cell Mater 20: 295-305.

Peister A, Mellad JA, Larson BL, Hall BM, Gibson LF, Prockop DJ (2004) Adult stem cells from bone marrow (MSCs) isolated from different strains of inbred mice vary in surface epitopes, rates of proliferation, and differentiation potential. Blood 103: 1662-1668.

Pereira RF, O’Hara MD, Laptev AV, Halford KW, Pollard MD, Class R, Simon D, Livezey K, Prockop DJ (1998) Marrow stromal cells as a source of progenitor cells for nonhematopoietic tissues in transgenic mice with a phenotype of osteogenesis imperfecta. Proc Natl Acad Sci USA 95: 1142-1147.

Pierdomenico L, Bonsi L, Calvitti M, Rondelli D, Arpinati M, Chirumbolo G, Becchetti E, Marchionni C, Alviano F, Fossati V, Staffolani N, Franchina M, Grossi A, Bagnara GP (2005) Multipotent mesenchymal stem cells with immunosuppressive activity can be easily isolated from dental pulp. Transplantation 80: 836-842.

Pittenger MF, Mackay AM, Beck SC, Jaiswal RK, Douglas R, Mosca JD, Moorman MA, Simonetti DW, Craig S, Marshak DR (1999) Multilineage potential of adult human mesenchymal stem cells. Science 284: 143-147.

Planat-Benard V, Silvestre JS, Cousin B, André M, Nibbelink M, Tamarat R, Clergue M, Manneville C, Saillan-Barreau C, Duriez M, Tudgui A, Levy B, Pénicaud L, Casteilla L (2004) Plasticity of human adipose 
lineage cells toward endothelial cells: physiological and therapeutic perspectives. Circulation 109: 656-663.

Poliard A, Ronziere MC, Freyria AM, Lamblin D, Herbage D, Kellermann O (1999) Lineage-dependent collagen expression and assembly during osteogenic or chondrogenic differentiation of a mesoblastic cell line. Exp Cell Res 253: 385-395.

Priam F, Ronco V, Locker M, Bourd K, Bonnefoix M, Duchêne T, Bitard J, Wurtz T, Kellerman O, Goldberg M, Poliard A (2005) New cellular models for tracking the odontoblast phenotype. Arch Oral Biol 50: 271-277.

Prockop DJ (2007) "Stemness" does not explain the repair of many tissues by mesenchymal stem/multipotent stromal cells (MSCs). Clin Pharmacol Ther 82: 241-243.

Rammelt S, Corbeil D, Manthey S, Zwipp H, Hanisch U (2007) Immunohistochemical in situ characterization of orthopedic implants on polymethyl metacrylate embedded cutting and grinding sections. J Biomed Mater Res A 83: 313-322.

Robertson EJ (1987) Embryo-derived stem cell lines. From teratocarcinomas and embryonic stem cells, a practical approach. IRL Press, Oxford, pp 71-112.

Ruch JV (1998) Odontoblast commitment and differentiation. Biochem Cell Biol 76: 923-938.

Seo BM, Sonoyama W, Yamaza T, Coppe C, Kikuiri T, Akiyama K, Lee JS, Shi S (2008) SHED repair critical-size calvarial defects in mice. Oral Dis 14: 428-434.

Shi S, Robey PG, Gronthos S (2001) Comparison of human dental pulp and bone marrow stromal stem cells by cDNA microarray analysis. Bone 29: 532-539.

Six N, Decup F, Lasfargues JJ, Salih E, Goldberg M (2002) Osteogenic proteins (bone sialoprotein and bone morphogenetic protein-7) and dental pulp mineralization. J Mater Sci Mater Med 13: 225-232.

Sloan AJ, Smith AJ (2007) Stem cells and the dental pulp: potential roles in dentine regeneration and repair. Oral Dis 13: 151-157.

Smith AJ, Cassidy N, Perry H, Begue-Kirn C, Ruch JV, Lesot H (1995) Reactionary dentinogenesis. Int J Dev Biol 39: 273-280.

Stevens A, Zuliani T, Olejnik C, LeRoy H, Obriot H, Kerr-Conte J, Formstecher P, Baillez Y, Polakowska BR (2008) Human dental pulp stem cells differentiate into neural crest-derived melanocytes and have label-retaining and sphere-forming abilities. Stem Cells Dev 17: 11751184.

Sun S, Guo Z, Xiao X, Liu B, Liu X, Tang PH, Mao $N$ (2003) Isolation of mouse marrow mesenchymal progenitors by a novel and reliable method. Stem Cells 21: $527-535$.

Tziafas D, Alvanou A, Papadimitriou S, Gasic J, Komnenou A (1998) Effects of recombinant basic fibroblast growth factor, insulin-like growth factor-II and transforming growth factor-beta 1 on dog dental pulp cells in vivo. Arch Oral Biol 43: 431-444.

Yamazaki H, Tsuneto M, Yoshino M, Yamamura K, Hayashi S (2007) Potential of dental mesenchymal cells in developing teeth. Stem Cells 25: 78-87.

Zhang W, Walboomers XF, Shi S, Fan M, Jansen JA (2006) Multilineage differentiation potential of stem cells derived from human dental pulp after cryopreservation. Tissue Eng 12: 2813-2823.

Zuk PA, Zhu M, Ashjian P, De Ugarte DA, Huang JI, Mizuno H, Alfonso ZC, Fraser JK (2002) Human adipose tissue is a source of multipotent stem cells. Mol Biol Cell 13: 4279-4295.

\section{Discussion with Reviewers}

Reviewer I: The authors have demonstrated the coexistence of clonal precursor (embryonic) cells with dissimilar potential for odonto/osteogenic differentiation in vitro and most remarkably in vivo. Can the authors elaborate on the potential applications of the most potent clone (upon expansion and maybe further modification) for regenerative medicine? Besides, do the authors expect that the concept can apply for other differentiation pathways, for instance for the treatment of cartilage defects or OA? Authors: Our study deals with in vitro models of mouse dental pulp "stem" cells and as such can only be used in animal models. From the available data, it is highly probable that equivalent progenitor cells are also present in the human pulp.

The take home message of our study is that like bone marrow and likely other adult tissues, the dental pulp contains subpopulations of progenitor cells with various potential of differentiation (multi-, bi-, or monopotent) towards, at least, the odonto/osteogenic, chondrogenic or adipogenic programme and that selection of one of these particular progenitor subpopulations based on a combination of cell surface markers allows to obtain a progenitor population more efficient/modular in repair than the bulk stem cell population obtained by simple selection on STRO-1 expression or low density inoculation.

This hypothesis has to be further tested in vivo, using cells directly selected from the pulp and implanted in their proper microenvironment, which is going to "direct" them towards a particular fate. Only these in vivo experiments will allow determining which type of progenitors (multi $v s$. more restricted) is more adequate/efficient to use for the defect repair and it seems already evident at this point that this will vary depending on the type of lesions to be treated. This is why, in the context of regenerative medicine, it might be important to have a better insight on the cascade of differentiation and to dispose of different types of progenitor populations.

As shown, the multipotent A4 clone can efficiently be recruited toward the chondrogenic fate in vitro and therefore A4 has an intrinsic potential for cartilage formation. However, this capacity has to be tested in vivo in the chondrogenic context of an appropriate model of the cranial sphere, before any clinical trial may be envisioned. We have not yet performed any experiment in this direction.

Reviewer II: Is it possible to use the results of this research for translational medicine?

Authors: Yes, we believe it will be used in the near future. As pointed out at the end of the Discussion "Because the mouse dental pulp clones express a set of cell surface 
molecules similar to that of human dental pulp stem cells, they constitute valuable tools to phenotypically define distinct types of cell progenitors, based on the sorting of subpopulations expressing different levels of cell surface molecules such as CD90 which can then be evaluated for their repair potential in dental pulp but also other craniofacial tissue lesions.".

This can be done of course with primary mouse pulpal progenitors but the idea is also to switch directly to their human counterparts, and through the analysis of the in vivo differentiation potential in relation to the level of expression of the cell surface markers (low, intermediate, high) to define a phenotype of pulpal progenitor populations that is more efficient than other cell populations in performing tissue repair in a particular pathological context (bone or pulp or neuronal lesions). Their specific "fishing out", on the basis of this variable CD expression level might then considerably improve the accuracy and reproducibility of the therapeutic processes since it will lead to more homogeneous cell populations than unselected or "grossly" selected ones. Such an approach has already proven successful for haematopoietic stem/progenitor cells. 